\title{
Risk Factor Profiles Achieved with Medical Therapy in Prevalent Patients with Pulmonary Arterial and Distal Chronic Thromboembolic Pulmonary Hypertension
}

\author{
Philipp Bartenstein Stéphanie Saxer Paula Appenzeller Mona Lichtblau \\ Esther I. Schwarz Silvia Ulrich \\ Clinic of Pulmonology, University Hospital Zurich, Zurich, Switzerland
}

\section{Keywords \\ Pulmonary arterial hypertension - Chronic thromboembolic pulmonary hypertension · Combination therapy · Risk stratification - Therapeutic goals}

\begin{abstract}
Background: The latest pulmonary hypertension $(\mathrm{PH})$ guidelines define therapeutic goals in terms of symptoms, exercise capacity, and haemodynamics for patients with pulmonary arterial hypertension (PAH) and recommend advanced combined medical therapy. For inoperable or post-surgical residual distal chronic thromboembolic $\mathrm{PH}$ (CTEPH) medical treatment is similarly advised. Objectives: We analysed whether risk factor goals are achieved and combination therapy is used in prevalent patients with $\mathrm{PAH}$ or distal CTEPH. Methods: PAH or distal CTEPH patients who were seen at the University Hospital Zurich during the last year were analysed in terms of demography, clinical data, medication, and therapeutic goals. Achievement of therapeutic goals was defined as New York Heart Association (NYHA) class $\leq \mathrm{Il}$, N-terminal pro-brain natriuretic peptide (NTpro$\mathrm{BNP})<300 \mathrm{ng} / \mathrm{L}$, and 6-min walking distance (6MWD) $>440$ m. Results: A total of $108 \mathrm{PAH}$ patients (age $59 \pm 18$ years, $62 \%$ female, $64 \%$ idiopathic, $36 \%$ associated) and 38
\end{abstract}

(c) 2018 S. Karger AG, Basel

E-Mail karger@karger.com www.karger.com/res distal CTEPH patients (age $69 \pm 14$ years, 55\% female) were included. They had been diagnosed on average $66 \pm 48$ months $( \pm S D$ ) previously. The percentage of PAH/CTEPH patients with NYHA $\leq I l$ was $52 / 53$, respectfully, the percentage of those with NTproBNP $<300 \mathrm{ng} / \mathrm{L}$ was $61 / 52$, and with 6 MWD $>440 \mathrm{~m} 63 / 50$. Overall, $33 / 31 \%$ fulfilled 3 and $29 / 35 \%$ fulfilled 2 of these goals. Regarding therapy, $43 \%$ of $\mathrm{PAH}$ patients were on double and $10 \%$ on triple combination therapy, whereas $16 \%$ of distal CTEPH patients were on double and $3 \%$ on triple combination therapy. Conclusions: In this real-life cohort of prevalent patients with PAH or distal $\mathrm{CTEPH}$, targeted drug therapy resulted in an achievement of $\geq 2 / 3$ predefined therapeutic goals in $2 / 3$ of patients. $\mathrm{Pa}$ tients with $\mathrm{PAH}$ were more likely to receive combination therapy compared to CTEPH patients. @ 2018 S. Karger AG, Basel

\section{Introduction}

The main symptom of precapillary pulmonary hypertension $(\mathrm{PH})$ is progressive dyspnoea on exertion associated with reduced daily activity and impaired quality of life $[1,2]$. In the absence of relevant lung disease, the main forms of precapillary $\mathrm{PH}$ are pulmonary arterial hy- 
pertension (PAH) and chronic thromboembolic $\mathrm{PH}$ (CTEPH) [3]. Guidelines recommend regular assessment of the severity and prognosis of $\mathrm{PH}$ using multidimensional risk stratification including clinical, haemodynamic, and exercise data employing defined parameters with known prognostic significance [3]. Recent data have confirmed the prognostic value of these risk factors at baseline and have shown that achievement of goals including mere clinical data are of prognostic importance during initial follow-up [4-6]. Of interest, the prognosis of patients achieving these goals at follow-up on therapy was comparable to patients who already presented with a favourable risk factor profile. According to the French registry, follow-up assessments using brain natriuretic peptides (BNP) as a substitute for invasive pulmonary haemodynamics in addition to New York Heart Association (NYHA) functional class and 6-min walking distance (6MWD) accurately predicted transplant-free survival in patients with idiopathic, hereditable, or drug- and toxininduced PAH [4].

During the last decades, several novel drugs were approved for PAH [3]. More than half of CTEPH patients can be treated and substantially ameliorated with pulmonary endarterectomy [7-9] and recently, significant functional improvements have been demonstrated with balloon pulmonary angioplasty in a further subgroup [10, 11]. The remaining patients with surgically inaccessible or post-interventional residual $\mathrm{PH}$ due to additional distal involvement (summarised as distal CTEPH) show similarities with $\mathrm{PAH}$ and are accordingly treated with drug therapy [12-15]. Combination drug therapy has been recommended in the latest guidelines for patients with $\mathrm{PAH}$ who do not achieve therapeutic goals in terms of symptoms, exercise capacity, and haemodynamics, and studies have shown an additional benefit of combination compared to a single drug therapy $[16,17]$. The efficacy of combination therapy in distal CTEPH is less clear due to lack of studies. However, from a pathophysiological perspective, distal CTEPH might be expected to respond comparably to $\mathrm{PAH}[13]$ and thus an increasing number of $\mathrm{PH}$ centres also use combination therapy in patients with distal CTEPH $[3,18]$.

Studying real-life cohorts enhances the understanding of epidemiology and treatment outcomes and is less susceptible to selection bias. However, cohort studies usually provide less comprehensive data compared to prospective controlled trials and their findings have to be interpreted with caution due to lack of blinding and a comparative control group. Nevertheless, real-life data complement the knowledge gained in clinical trials. Over the last 2 decades, prognostic data from different registries have been published [18-25]. Most analyses included only incident patients with PAH and analysed parameters at baseline or during a short-term follow-up [4-6, 26]. However, little is known about the achievement of predefined therapeutic goals in prevalent patients with $\mathrm{PAH}$ /distal CTPEH in real life and the long-term course on drug therapy. We thus reviewed all prevalent patients with PAH or distal CTPEH seen at least once between November 2015 and November 2016 at our institution and analysed to which extent the basic therapeutic goals (according to $\mathrm{PH}$ guidelines and recently published cohort data) are achieved on which drug regimens. We therefore focused on assessing NYHA functional class, exercise capacity measured by the $6 \mathrm{MWD}$, and right ventricular function by measuring $\mathrm{N}$-terminal pro-BNP (NTproBNP).

\section{Methods}

Patients with PAH or CTEPH treated in the PH centre of the University Hospital Zurich who gave written informed consent to be registered and followed up in an internal pseudonymised database were checked for eligibility. The study was approved by the local ethics committee of Zurich (Req-2016-00786) and registered on clinicaltrials.gov (NCT03198910).

$\mathrm{PAH}$ and CTEPH were diagnosed and classified according to the latest guidelines [12]. PAH subgroups with idiopathic/heritable PAH (IPAH) and associated with connective tissue disease, human immunodeficiency virus, portal hypertension, and congenital heart disease were eligible. As genetic testing for $\mathrm{PAH}$ is not reimbursed by Swiss health insurance companies, idiopathic and hereditary PAH were summarised as IPAH. Distal CTEPH was defined as either inoperable or persistent $\mathrm{PH}$ after pulmonary endarterectomy. All prevalent patients (diagnosed $>12$ months previously) with $\mathrm{PAH} /$ distal CTEPH who were seen at the PH centre of the University Hospital Zurich between November 2015 and November 2016 were analysed.

Patient characteristics (age, gender, BMI, PH group) and pulmonary haemodynamics assessed by diagnostic right heart catheterisation were retrieved at the time of diagnosis and the following data during regular follow-up after 3, 6, and 12 months and at the last prevalent visit: NYHA class, 6MWD, and NTproBNP. The following three thresholds of these outcome parameters were used to assess the achievement of treatment goals during routine follow-up: NYHA class $\leq$ II, NTproBNP $<300 \mathrm{ng} / \mathrm{L}$, and $6 \mathrm{MWD}$ $>440 \mathrm{~m}$. These three parameters are, amongst others, associated with a 1 -year mortality risk $<5 \%$ [12]. Patients whose parameters were available at least at the time of diagnosis and the last prevalent visit were included (main group). For a more detailed insight, a subgroup which had at least 3 out of the 5 time points (diagnosis, after 3, 6, and 12 months, last prevalent visit) were analysed separately (comprehensive subgroup). The last prevalent visit was defined as the last visit the patient had in the evaluated period. 
PH-targeted drug therapy included endothelin receptor antagonists (ERA), prostanoids, phosphodiesterase type 5 inhibitors (PDE-5-I), soluble guanylate cyclase stimulator (sGC), or highdose calcium channel blockers in cases of vasoactive PAH.

Analyses were performed using SPSS Statistics version 23 (SPSS, Chicago, IL, USA). Data were summarised as means (standard deviation or percentages) and medians (quartiles) according to normal or non-normal distribution. Differences between groups were assessed by independent $t$ tests or Mann-Whitney $\mathrm{U}$ tests according to normality distribution. Baseline and follow-up data (changes over time) were compared using analysis of variance (ANOVA), paired $t$ tests, or Wilcoxon tests. Multiple regression was used to study factors influencing outcomes. A two-sided $p$ value $<0.05$ was considered statistically significant.

\section{Results}

\section{Patient Characteristics}

A total of 143 of 313 patients (105 PAH, 38 distal CTEPH) fulfilled the inclusion criteria and had data available at least at diagnosis and at the last prevalent visit. The flow of patients throughout the study is shown in Figure 1. Characteristics of patients with PAH and CTEPH are shown in Tables 1 and 2, respectively. Patients with PAH were younger than those with CTEPH without other demographic differences. Most patients with PAH were idiopathic $(63 \%)$ or connective tissue disease-associated (20\%); $77 \%$ of the patients with PAH were treated with ERA, $12 \%$ with prostanoids, $56 \%$ with PDE-5-I, and $10 \%$ with sGC. $44 \%$ were on double and $10 \%$ on triple combination therapy. The median follow-up time of PAH patients was 50 (29; 93) months (range 14-274 months). During follow-up, NYHA class significantly improved from $3(2 ; 3)$ to $2(2 ; 3)(p<0.05)$; in particular, the number of patients in NYHA class I increased from 1 to $12 \%$. $6 \mathrm{MWD}$ and NTproBNP remained unchanged.

Most patients with distal CTEPH were inoperable and treated with ERA (50\%), prostanoids (3\%), PDE-5-I (21\%), and sGC stimulator (42\%); $81 \%$ received a single drug, $16 \%$ were on a double, and $3 \%$ on a triple combination therapy. The median follow-up time of distal CTEPH was $40(25 ; 103)$ months (range of $12-173$ months). 6MWD and NTproBNP did not change significantly during follow-up. However, NYHA class significantly improved from $3(2 ; 3)$ to $2(2 ; 3)(p<0.05)$. The percentage of patients with NYHA functional class I and II increased by 11 and 10\%, respectively, from NYHA class III and IV.

\section{Monotherapy versus Combination Therapy}

Of patients with $\mathrm{PAH}, 48$ were on a single drug (including 7 on high-dose calcium channel blockers due to

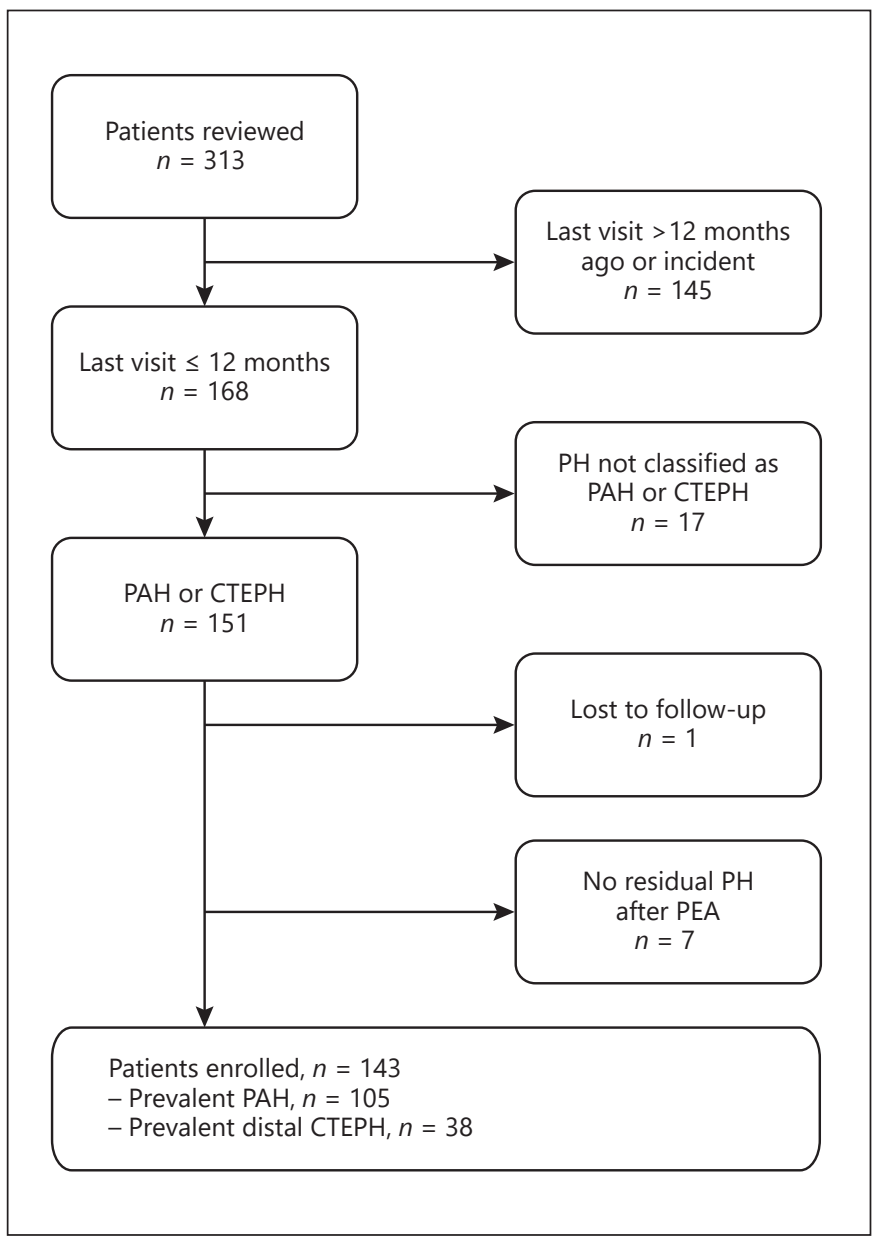

Fig. 1. Flowchart of patients throughout the study. $\mathrm{PH}$, pulmonary hypertension; $\mathrm{PAH}$, pulmonary arterial hypertension; CTEPH, chronic thromboembolic pulmonary hypertension; PEA, pulmonary endarterectomy.

vasoactive $\mathrm{PAH}$ ) and 57 were on combination therapy (Tables 1,3). Age and BMI of patients in the single versus combination therapy groups did not differ at the time of diagnosis. Patients receiving monotherapy had a lower NTproBNP and mPAP and a higher cardiac index compared to those receiving combination therapy and tended to have a longer 6MWD and lower NYHA class. The change of NYHA functional class $(p=0.070), 6 \mathrm{MWD}$ $(p=0.990)$, and NTproBNP $(p=0.208)$ over time (first visit to last prevalent visit) did not differ between the two groups. Patients with combination therapy tended to be treated for a longer time than those with single therapy (58 [30; 110] vs. $46[27 ; 82]$ months).

Only 7 of 38 patients with distal CTEPH received combination therapy (Tables 2, 3). At the time of diagnosis, 
Table 1. Characteristics of 105 prevalent patients with PAH

\begin{tabular}{|c|c|c|c|c|}
\hline & Diagnosis & $n$ & $\begin{array}{l}\text { Last pre- } \\
\text { valent visit }\end{array}$ & $n$ \\
\hline Females & $65(62)$ & 105 & & \\
\hline Age, years & $55(38 ; 70)$ & 105 & $59(44 ; 75)^{*}$ & 105 \\
\hline $\mathrm{BMI}$ & $26(22 ; 29)$ & 101 & $26(22 ; 29)$ & 92 \\
\hline \multicolumn{5}{|l|}{ Cardiac index, L/min/ } \\
\hline & $2.7(2.2 ; 3.2)$ & 96 & & \\
\hline mPAP, mm Hg & $43(32 ; 54)$ & 102 & & \\
\hline $\mathrm{RAP}, \mathrm{mm} \mathrm{Hg}$ & $7(5 ; 10)$ & 99 & & \\
\hline Follow-up, months & & & $50(29 ; 93)$ & 105 \\
\hline \multicolumn{5}{|l|}{ PAH classification } \\
\hline Idiopathic/heritable & $66(63)$ & & & \\
\hline $\begin{array}{l}\text { Connective tissue dis- } \\
\text { ease }\end{array}$ & $21(20)$ & & & \\
\hline HIV infection & $2(2)$ & & & \\
\hline Portal hypertension & $3(3)$ & & & \\
\hline $\begin{array}{l}\text { Congenital heart dis- } \\
\text { ease }\end{array}$ & $13(12)$ & & & \\
\hline \multicolumn{5}{|l|}{ PAH therapy } \\
\hline ERA & $81(77)$ & & & \\
\hline Prostanoid & $13(12)$ & & & \\
\hline PDE-5-I & $59(56)$ & & & \\
\hline sGC & $11(10)$ & & & \\
\hline Monotherapy & $48(46)$ & & & \\
\hline Double combination & $46(44)$ & & & \\
\hline Triple combination & $11(10)$ & & & \\
\hline \multicolumn{5}{|l|}{ Follow-up parameters } \\
\hline NYHA functional class & $3(2 ; 3)$ & 99 & $2(2 ; 3)^{*}$ & 105 \\
\hline NYHA I & $1(1)$ & & $13(12)$ & \\
\hline NYHA II & $34(34)$ & & $42(40)$ & \\
\hline NYHA III & $52(53)$ & & $41(39)$ & \\
\hline NYHA IV & $12(12)$ & & $9(9)$ & \\
\hline 6MWD, m & $\begin{array}{l}471 \\
(363 ; 565)\end{array}$ & 90 & $\begin{array}{l}480 \\
(402 ; 565)\end{array}$ & 79 \\
\hline NTproBNP, ng/L & $\begin{array}{l}420 \\
(159 ; 989)\end{array}$ & 83 & $\begin{array}{l}217 \\
(83 ; 847)\end{array}$ & 75 \\
\hline
\end{tabular}

Data are shown as median (quartiles) or $n$ (\%). PAH, pulmonary arterial hypertension; BMI, body mass index; mPAP, mean pulmonary arterial pressure; RAP, right atrial pressure; HIV, human immunodeficiency virus; ERA, endothelin receptor antagonist; PDE-5-I, phosphodiesterase type 5 inhibitor; sGC, soluble guanylate cyclase stimulator; NYHA, New York Heart Association; 6MWD, 6-min walking distance; NTproBNP, N-terminal pro-brain natriuretic peptide. ${ }^{*} p<0.001$ versus diagnosis.

these 7 patients had a significantly higher NTproBNP and mPAP compared to patients receiving monotherapy. CTEPH patients on combination therapy also tended to be younger and have a lower 6MWD and cardiac index than those treated with monotherapy. When comparing
Table 2. Characteristics of 38 prevalent patients with CTEPH

\begin{tabular}{|c|c|c|c|c|}
\hline & Diagnosis & $n$ & $\begin{array}{l}\text { Last pre- } \\
\text { valent visit }\end{array}$ & $n$ \\
\hline Females & $21(55)$ & 38 & & \\
\hline Age, years & $67(57 ; 73)$ & 38 & $72(60 ; 80)^{*}$ & 38 \\
\hline BMI & $27(23 ; 32)$ & 38 & $27(25 ; 32)$ & 32 \\
\hline \multicolumn{5}{|l|}{ Cardiac index, } \\
\hline $\mathrm{L} / \mathrm{min} / \mathrm{m}^{2}$ & $2.7(2.4 ; 3.0)$ & 36 & & \\
\hline mPAP, mm Hg & $36(32 ; 48)$ & 37 & & \\
\hline $\mathrm{RAP}, \mathrm{mm} \mathrm{Hg}$ & $8(4 ; 13)$ & 35 & & \\
\hline Follow-up, months & & & $40(25 ; 103)$ & 38 \\
\hline \multicolumn{5}{|l|}{ CTEPH classification } \\
\hline Inoperable & $30(79)$ & & & \\
\hline Persistent $\mathrm{PH}$ after PEA & $8(21)$ & & & \\
\hline \multicolumn{5}{|l|}{ CTEPH therapy } \\
\hline ERA & $19(50)$ & & & \\
\hline Prostanoid & $1(3)$ & & & \\
\hline PDE-5-I & $8(21)$ & & & \\
\hline sGC & $16(42)$ & & & \\
\hline Monotherapy & $31(81)$ & & & \\
\hline Double combination & $6(16)$ & & & \\
\hline Triple combination & $1(3)$ & & & \\
\hline \multicolumn{5}{|l|}{ Follow-up parameters } \\
\hline NYHA functional class & $3(2 ; 3)$ & 38 & $2(2 ; 3)^{* *}$ & 38 \\
\hline NYHA I & $0(0)$ & & $4(11)$ & \\
\hline NYHA II & $12(32)$ & & $16(42)$ & \\
\hline NYHA III & $19(50)$ & & $15(39)$ & \\
\hline NYHA IV & $7(18)$ & & $3(8)$ & \\
\hline 6MWD, m & $\begin{array}{l}494 \\
(334 ; 575)\end{array}$ & 33 & $\begin{array}{l}480 \\
(360 ; 580)\end{array}$ & 31 \\
\hline NTproBNP, ng/L & $\begin{array}{l}490 \\
(121 ; 1,596)\end{array}$ & 31 & $\begin{array}{l}289 \\
(146 ; 877)\end{array}$ & 29 \\
\hline
\end{tabular}

Data are shown as median (quartiles) or $n$ (\%). CTEPH, chronic thromboembolic pulmonary hypertension; BMI, body mass index; mPAP, mean pulmonary arterial pressure; RAP, right atrial pressure; PEA, pulmonary endarterectomy; ERA, endothelin receptor antagonists; PDE-5-I, phosphodiesterase type 5 inhibitor; sGC, soluble guanylate cyclase stimulator; NYHA, New York Heart Association; 6MWD, 6-min walking distance; NTproBNP, $\mathrm{N}$-terminal pro-brain natriuretic peptide. ${ }^{*} p<0.001$ versus diagnosis; ${ }^{* *} p=0.001$ versus diagnosis.

changes over time (first vs. last prevalent visit) in patients with CTEPH, the only significant difference between single and combination therapy was found in NTproBNP $(p=0.040)$, whereby combination therapy resulted in a larger reduction in NT-proBNP.

\section{Achievement of Therapeutic Goals}

At the time of diagnosis, $35 \%$ of $\mathrm{PAH}$ patients were already in NYHA class $\leq \mathrm{II}, 43 \%$ had a NTproBNP $<300$
Bartenstein/Saxer/Appenzeller/Lichtblau/ Schwarz/Ulrich 
Table 3. Prevalent patients with PAH or distal CTEPH grouped according to their pulmonary hyper-tensiontargeted therapy (monotherapy vs. combination therapy)

\begin{tabular}{|c|c|c|c|c|}
\hline \multirow[t]{2}{*}{ PAH } & \multicolumn{2}{|c|}{ Monotherapy, $n=48$ (46\%) } & \multicolumn{2}{|c|}{ Combination therapy, $n=57$ (54\%) } \\
\hline & diagnosis & last prevalent visit & diagnosis & last prevalent visit \\
\hline Age, years & $55(37 ; 71)$ & $60(43 ; 75)$ & $55(38 ; 70)$ & $59(46 ; 75)$ \\
\hline $\mathrm{BMI}$ & $26(22 ; 30)$ & $26(21 ; 29)$ & $25(22 ; 29)$ & $26(22 ; 29)$ \\
\hline NYHA functional class & $3(2 ; 3)$ & $2(2 ; 3)$ & $3(2 ; 3)$ & $3(2 ; 3)^{\circ}$ \\
\hline $6 \mathrm{MWD}, \mathrm{m}$ & $483(395 ; 585)$ & $456(424 ; 589)$ & $455(338 ; 533)$ & $480(348 ; 560)$ \\
\hline NTproBNP, ng/L & $196(135 ; 612)$ & $130(63 ; 263)$ & $730(211 ; 1,741)^{*}$ & $379(107 ; 1,073)^{\circ}$ \\
\hline \multicolumn{5}{|l|}{ Cardiac index, } \\
\hline $\mathrm{L} / \mathrm{min} / \mathrm{m}^{2}$ & \multicolumn{2}{|l|}{$3.0(2.4 ; 3.4)$} & \multicolumn{2}{|l|}{$2.4(2.1 ; 3.0)^{*}$} \\
\hline mPAP, mm Hg & \multicolumn{2}{|l|}{$34(27 ; 44)$} & \multicolumn{2}{|l|}{$51(40 ; 59)^{*}$} \\
\hline \multirow[t]{2}{*}{ Distal CTEPH } & \multicolumn{2}{|c|}{ Monotherapy, $n=31$ (82\%) } & \multicolumn{2}{|c|}{ Combination therapy, $n=7(18 \%)$} \\
\hline & diagnosis & last prevalent visit & diagnosis & last prevalent visit \\
\hline Age, years & $68(58 ; 73)$ & $73(63 ; 81)$ & $61(38 ; 64)$ & $62(44 ; 76)$ \\
\hline BMI & $28(23 ; 32)$ & $27(25 ; 32)$ & $27(23 ; 38)$ & $27(21 ; 34)$ \\
\hline NYHA functional class & $3(2 ; 3)$ & $2(2 ; 3)$ & $3(2 ; 3)$ & $2(2 ; 3)$ \\
\hline $6 \mathrm{MWD}, \mathrm{m}$ & $500(368 ; 590)$ & $490(387 ; 597)$ & $403(278 ; 504)$ & $368(300 ; 435)^{\circ}$ \\
\hline NTproBNP, ng/L & $274(111 ; 1,334)$ & $208(124 ; 709)$ & $2,004(846 ; 2,921)^{*}$ & $1,454(846 ; 2,921)^{\circ}$ \\
\hline \multicolumn{5}{|l|}{ Cardiac index, } \\
\hline $\mathrm{L} / \mathrm{min} / \mathrm{m}^{2}$ & $2.7(2.4 ; 3.1)$ & & $2.3(1.9 ; 2.7)$ & \\
\hline mPAP, mm Hg & $35(29 ; 44)$ & & $48(46 ; 54)^{*}$ & \\
\hline
\end{tabular}

Data are shown as median (quartiles) or $n(\%)$. PAH, pulmonary arterial hypertension; CTEPH, chronic thromboembolic pulmonary hypertension; NYHA, New York Heart Association; 6MWD, 6-min walking distance; NTproBNP, N-terminal pro-brain natriuretic peptide; mPAP, mean pulmonary arterial pressure. ${ }^{*} p<$ $0.05 \mathrm{no} /$ monotherapy at diagnosis versus combination therapy at diagnosis; ${ }^{\circ} p<0.05 \mathrm{no} /$ monotherapy at last visit versus combination therapy at last visit.

ng/L, and 58\% a $6 \mathrm{MWD}>440 \mathrm{~m}$ (Table 4); $13 \%$ fulfilled all three low-risk criteria, $34 \%$ two, $28 \%$ one, and $25 \%$ none. Up to the last prevalent visit, all three therapeutic goals were fulfilled by more than half of $\mathrm{PAH}$ patients and the number of patients that fulfilled three criteria considerably increased by $20 \%$ at the expense of fulfilling only two, one, or none of the goals $(-5,-4$, and $-11 \%$, respectfully).

In patients with distal CTEPH, the distribution of the risk profile according to the predefined thresholds in NYHA class, 6MWD, and NTproBNP was similar to patients with $\mathrm{PAH}$ at diagnosis; $14 \%$ fulfilled all three criteria, $39 \%$ two, $18 \%$ one, and $29 \%$ none. Up to the last prevalent visit, fulfilling three, two, one, and no lowrisk criteria changed by $+17,-4,+1$, and $-14 \%$, respectively.
Change in Risk Factor Profile over Time in Patients with More Complete Datasets

This prevalent subgroup of $\mathrm{PAH}$ with more comprehensive data available was seen in 2016 and on average diagnosed in 2014 (range from 2011 to 2015). At the time of diagnosis, $82 \%$ of this PAH subgroup received a single drug and $18 \%$ started directly with combination therapy. Over all time points, continuously more patients received combination therapy resulting in a 1:1 ratio of single versus combination therapy after a median follow-up time of $21(17 ; 36)$ months. As shown in Table 5 and Figure 2, this PAH group significantly improved their NYHA class over all time points. The percentage of patients with NYHA class $\leq \mathrm{II}$ increased from 32 to $60 \%$. The $6 \mathrm{MWD}$ stabilised around baseline value, with a peak of $536 \mathrm{~m}$ (420; 630) after 12 months. NTproBNP changed significantly after 3 and 6 months. After 12 months, NTproBNP was $157 \mathrm{ng} / \mathrm{L}(59 ; 463)$ at its lowest (Fig. 3). 
Table 4. Therapeutic goals achieved in patients with PAH and distal CTEPH

\begin{tabular}{|c|c|c|c|c|c|c|c|c|}
\hline & \multicolumn{4}{|l|}{ PAH } & \multicolumn{4}{|c|}{ Distal CTEPH } \\
\hline & diagnosis & $n$ & $\begin{array}{l}\text { last pre- } \\
\text { valent visit }\end{array}$ & $n$ & diagnosis & $n$ & $\begin{array}{l}\text { last pre- } \\
\text { valent visit }\end{array}$ & $n$ \\
\hline NYHA $\leq$ II & $35(35)$ & 99 & $55(52)$ & 105 & $12(32)$ & 38 & $20(53)$ & 38 \\
\hline NTproBNP <300 ng/L & $36(43)$ & 83 & $46(61)$ & 75 & $13(42)$ & 31 & $15(52)$ & 29 \\
\hline $6 \mathrm{MWD}>440 \mathrm{~m}$ & $52(58)$ & 90 & $50(63)$ & 79 & $21(64)$ & 33 & $18(58)$ & 31 \\
\hline All 3 criteria & $10(13)$ & 76 & $21(33)$ & 63 & $4(14)$ & 28 & $8(31)$ & 26 \\
\hline 2 criteria & $26(34)$ & 76 & $18(29)$ & 63 & $11(39)$ & 28 & $9(35)$ & 26 \\
\hline 1 criterion & $21(28)$ & 76 & $15(24)$ & 63 & $5(18)$ & 28 & $5(19)$ & 26 \\
\hline No criterion & $19(25)$ & 76 & $9(14)$ & 63 & $8(29)$ & 28 & $4(15)$ & 26 \\
\hline
\end{tabular}

Data are shown as $n$ (\%). PAH, pulmonary arterial hypertension; CTEPH, chronic thromboembolic pulmonary hypertension; NYHA, New York Heart Association; 6MWD, 6-min walking distance; NTproBNP, N-terminal pro-brain natriuretic peptide.

Table 5. Changes of risk factor profiles over time in PAH or distal CTEPH patients with comprehensive datasets at most predefined time points followed up closely in a tertiary care centre

\begin{tabular}{|c|c|c|c|c|c|c|c|c|c|c|c|}
\hline & Diagnosis & $n$ & $\begin{array}{l}\text { 3-month } \\
\text { follow-up }\end{array}$ & $n$ & $\begin{array}{l}\text { 6-month } \\
\text { follow-up }\end{array}$ & $n$ & $\begin{array}{l}\text { 12-month } \\
\text { follow-up }\end{array}$ & $n$ & $\begin{array}{l}\text { Last prevalent } \\
\text { visit }\end{array}$ & $n$ & $\begin{array}{l}\text { ANOVA, } \\
\text { p value }\end{array}$ \\
\hline \multicolumn{12}{|l|}{$P A H$} \\
\hline BMI & $26(23 ; 29)$ & 47 & $26(23 ; 29)$ & 33 & $26(24 ; 31)$ & 32 & $25(23 ; 30)$ & 40 & $27(24 ; 30)$ & 43 & 0.571 \\
\hline NYHA functional class & $3(2 ; 3)$ & 46 & $2.5(2 ; 3)^{*}$ & 36 & $2.5(2 ; 3)^{*}$ & 40 & $2(2 ; 3)^{*}$ & 44 & $2(2 ; 3)^{*}$ & 50 & 0.004 \\
\hline NYHA I & $1(2)$ & & $6(17)$ & & $5(13)$ & & $7(16)$ & & $8(16)$ & & \\
\hline NYHA II & $14(30)$ & & $12(33)$ & & $15(38)$ & & $17(39)$ & & $22(44)$ & & \\
\hline NYHA III & $25(54)$ & & $16(44)$ & & $15(38)$ & & $14(32)$ & & $17(34)$ & & \\
\hline NYHA IV & $6(13)$ & & $2(6)$ & & $5(13)$ & & $6(14)$ & & $3(6)$ & & \\
\hline 6MWD, m & $482(369 ; 578)$ & 45 & $471(373 ; 560)$ & 34 & $464(388 ; 561)$ & 36 & $536(420 ; 630)$ & 39 & $480(418 ; 572)$ & 40 & 0.774 \\
\hline NTproBNP, ng/L & $236(135 ; 861)$ & 44 & $273(119 ; 470)^{*}$ & 27 & $243(101 ; 558)^{*}$ & 27 & $157(59 ; 463)$ & 35 & $180(73 ; 359)$ & 36 & 0.033 \\
\hline \multicolumn{12}{|l|}{ СТЕРH } \\
\hline BMI & $28(23 ; 34)$ & 20 & $28(23 ; 35)$ & 16 & $29(23 ; 34)$ & 15 & $25(23 ; 34)$ & 14 & $28(25 ; 35)$ & 16 & 0.849 \\
\hline NYHA functional class & $3(3 ; 4)$ & 20 & $3(2 ; 3)$ & 16 & $3(2 ; 4)$ & 16 & $2(2 ; 3)^{*}$ & 17 & $2.5(2 ; 3)^{*}$ & 20 & 0.004 \\
\hline NYHA I & $0(0)$ & & $0(0)$ & & $0(0)$ & & $3(18)$ & & $3(15)$ & & \\
\hline NYHA II & $4(20)$ & & $4(25)$ & & $6(38)$ & & $7(41)$ & & $7(35)$ & & \\
\hline NYHA III & $10(50)$ & & $10(63)$ & & $6(38)$ & & $6(35)$ & & $8(40)$ & & \\
\hline NYHA IV & $6(30)$ & & $2(13)$ & & $4(25)$ & & $1(6)$ & & $2(10)$ & & \\
\hline 6MWD, m & $438(280 ; 573)$ & 18 & $464(379 ; 538)$ & 14 & $444(348 ; 611)$ & 13 & $470(330 ; 602)$ & 17 & $470(348 ; 580)$ & 15 & 0.211 \\
\hline NTproBNP, ng/L & $745(215 ; 1544)$ & 18 & $1,658(137 ; 2629)$ & 11 & $755(337 ; 1601)$ & 12 & $550(95 ; 1498)$ & 15 & $320(132 ; 1,126)$ & 13 & 0.363 \\
\hline
\end{tabular}

Data are shown as median (quartiles) or $n$ (\%). PAH, pulmonary arterial hypertension; CTEPH, chronic thromboembolic pulmonary hypertension; NYHA, New York Heart Association; $6 \mathrm{MWD}, 6$-min walking distance; NTproBNP, N-terminal pro-brain natriuretic peptide; mPAP, mean pulmonary arterial pressure; ANOVA, analysis of variance. ${ }^{*} p<0.05$ versus diagnosis.

In patients with distal CTEPH and comprehensive data available, the median year of diagnosis was 2014, with a range from 2012 to 2015 (Table 5; Fig. 2). No significant change in BMI and NTproBNP was observed after 3,6 , or 12 months or at the last prevalent visit. The NYHA class decreased significantly from baseline to 12 months and at the last prevalent visit, whereas BMI, NTproBNP, and 6MWD remained unchanged (Fig. 3).

\section{Discussion}

In this real-life cohort of prevalent patients with $\mathrm{PAH}$ and distal CTEPH, we show that NYHA class was sustainably improved and 6MWD and NTproBNP maintained for on average more than 3 years after diagnoses on drug therapy. These beneficial effects were achieved with a close clinical follow-up and timely initiation of combination therapy, which was started initially in $18 \%$ of PAH 
Fig. 2. Change of New York Heart Association (NYHA) functional class over time in patients with pulmonary arterial hypertension (PAH) and chronic thromboembolic pulmonary hypertension (CTEPH).

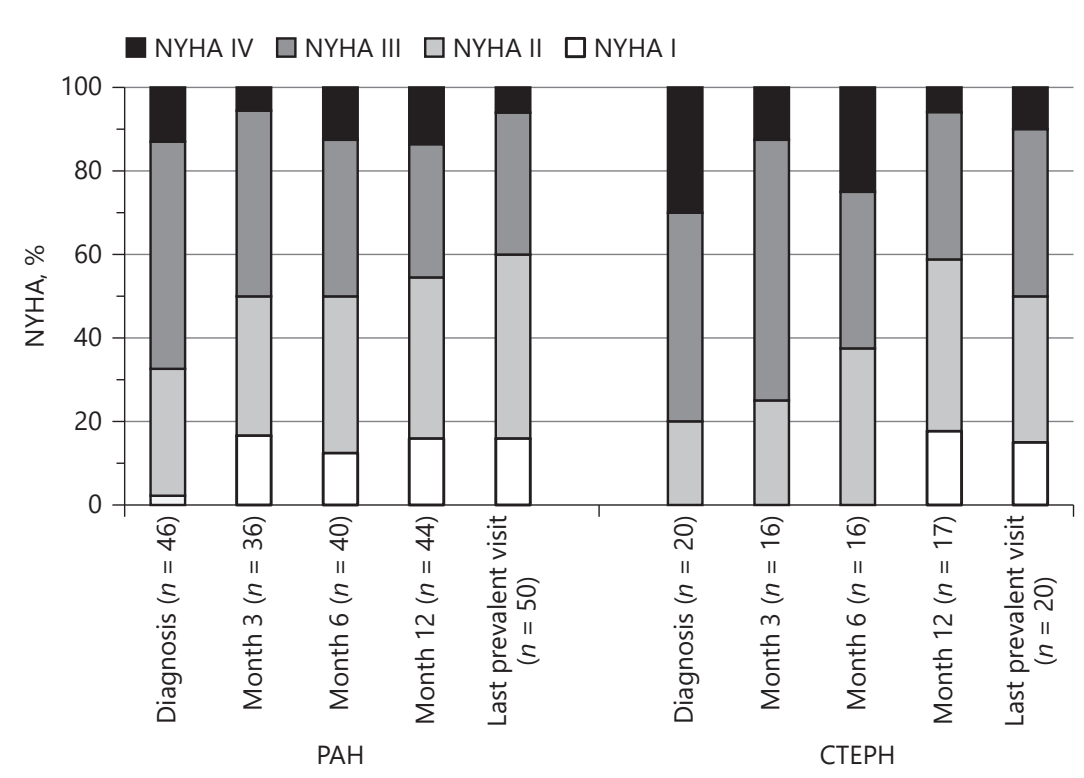

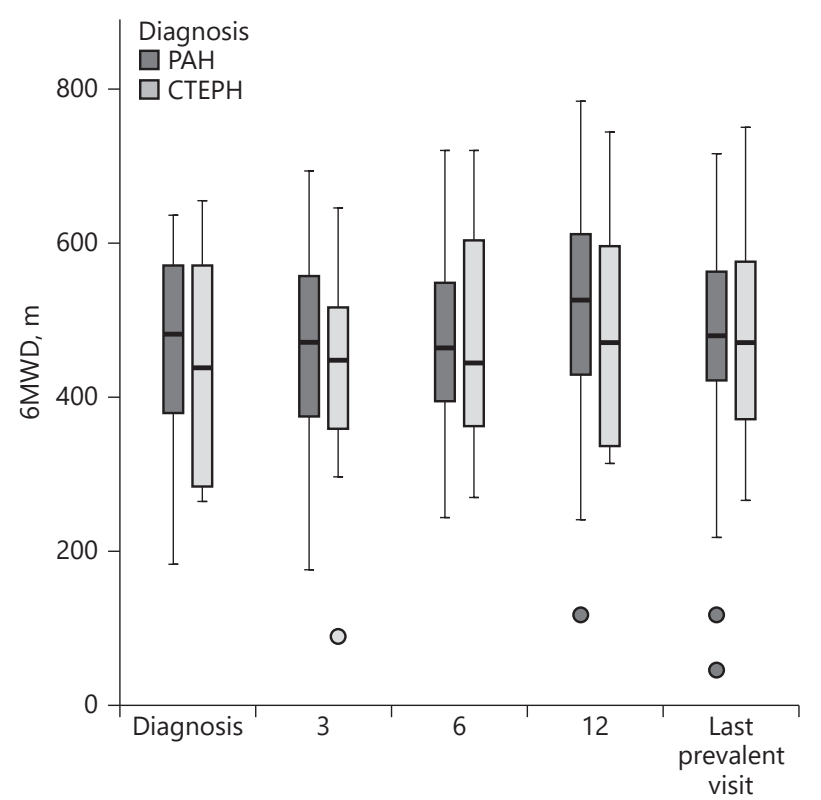

Time of visit, months

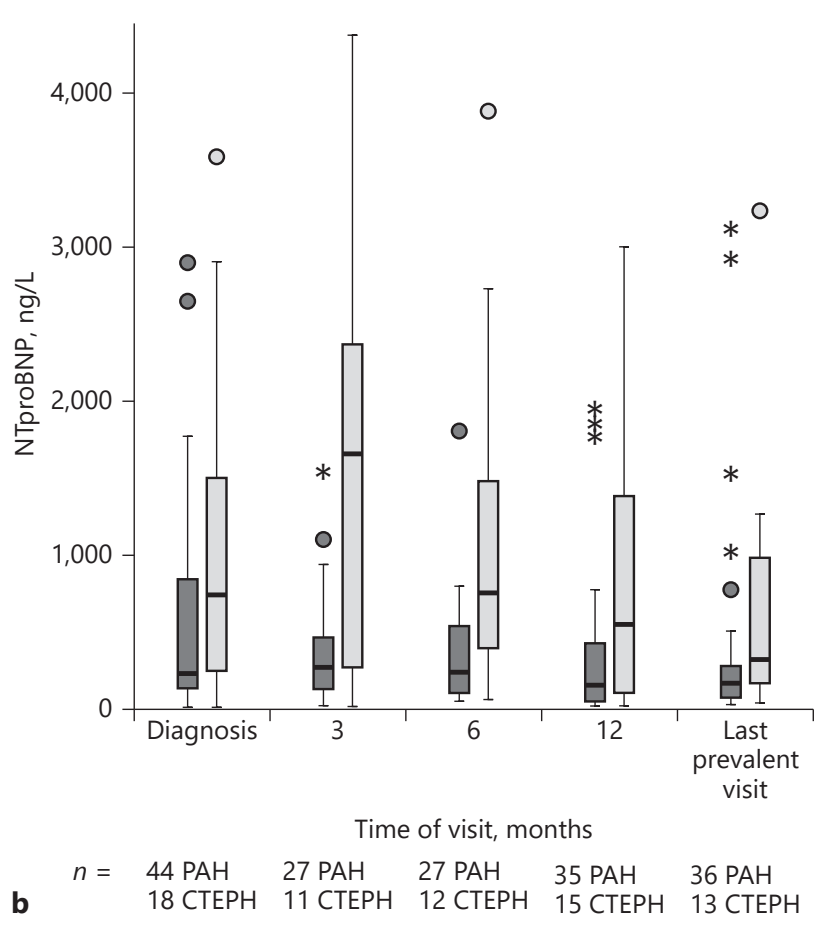

Fig. 3. a Change of 6-min walking distance (6MWD) over time in pulmonary arterial hypertension (PAH) and chronic thromboembolic pulmonary hypertension (CTEPH) with more complete datasets during follow-up over different time points. Shown as box plots (median; quartiles; ${ }^{\circ}$ outliers). b Change of $\mathrm{N}$-terminal pro- brain natriuretic peptide (NTproBNP) with more complete datasets during follow-up over different time points in $\mathrm{PAH}$ and CTEPH. Shown as box plots (median; quartiles; ${ }^{\circ}$ outliers; * extreme outliers). 
patients and increased to more than $50 \%$ after a median follow-up time of 21 months. Patients receiving combination therapy had higher NTproBNP and worse haemodynamics at diagnosis, indicating a more advanced disease state. This goal-oriented therapy in a real-life setting was not only associated with a higher number of patients being in favourable functional classes, but also an increased percentage of patients fulfilling the basic predefined therapeutic goals [3].

This study adds to the knowledge retrieved from other $\mathrm{PH}$ registries as it focuses on the clinical course and achievements of therapeutic goals of prevalent patients with PAH and distal CTEPH, which are known to behave differently compared to incident patients as included in most registries [8, 18, 25, 27-32]. This prevalent cohort of $\mathrm{PAH} /$ distal CTEPH provides real-life information on the effect of medical care and drug therapy on the progression of these chronic and formerly often rapidly fatal diseases. The amelioration of functional class and stabilisation of other risk factors along with an increasing number of patients fulfilling predefined therapeutic goals is reassuring that modern therapies help to improve the patient's condition in real life and indicates that the number of drugs prescribed nowadays reflects the severity of the disease $[3,33]$.

\section{Epidemiology and Clinical Pathway}

In the current observational cohort, the median age at the time of diagnosis was 55 years $(38 ; 70)$ for patients with PAH and 67 years $(57 ; 73)$ for patients with CTEPH, and is thus comparable to other national (Swiss, French, British, and American) and international cohorts $[8,18$, $21,25,27,29,34]$. While the NYHA class at the time of diagnosis was comparable to other registries, patients in our cohort had a better exercise capacity as assessed by the $6 \mathrm{MWD}$, which was about $100 \mathrm{~m}$ longer $[8,18,21,27$, 32]. One explanation could be the earlier detection of $\mathrm{PH}$ in recent years due to a higher awareness of physicians and other health care professionals indicating a betterpreserved physical function. However, patients in the present cohort were diagnosed at a relatively higher age compared to historical cohorts but comparable to recent registry data $[8,18,25,27,29]$. Another explanation might be that in the present cohort, we assessed prevalent patients, which per se are a selection of patients with an overall better prognosis and thus have better functional parameters [22]. Thus, a comparison between baseline data from earlier published registries and our prevalent cohort can only be made with caution, due to the different inclusion criteria and the assessment period.
PAH patients in the present cohort were treated with $\mathrm{PAH}$-targeted therapy. The majority of patients were diagnosed before the publication of the results of the ambition trial and latest guidelines $[3,16]$, which have shown a significantly lower risk of clinical failure events for initial combination therapy of ambrisentan and tadalafil compared to a single therapy with either one of these drugs. This study together with other recent results led to a paradigm shift in $\mathrm{PAH}$ therapy to early combination therapy $[3,35]$, although a goal-oriented strategy and initial combination therapy have never been directly compared in a randomised trial. In the present cohort of relatively low-risk prevalent patients, $82 \%$ initially started on monotherapy. The most frequently initiated drugs were ERAs, followed by PDE-5-I. These results correlate with previous data in Switzerland, but differ slightly from British or American cohorts, where PDE-5 inhibitors were used more often for initial treatment [27, 29]. The most frequent combination was ERA and PDE-5-I, as oral drugs were first combined before initiating a triple combination therapy including a parenteral prostanoid. Combination therapy was timely initiated in over half of the $\mathrm{PAH}$ patients even before clear clinical disease deterioration. In the present cohort, PAH patients who received combination therapy were in a clinically less favourable state with worse haemodynamics, functional class, and physical capacity as assessed by the $6 \mathrm{MWD}$, and presumably a more advanced disease state, which again indicates that a goal-oriented therapeutic strategy was applied.

Patients with distal CTEPH were more often treated with a single drug over the entire observational period. Less than $1 / 5$ of patients with distal CTEPH were treated with combination therapy, potentially related to the fact that patients with distal CTEPH in this cohort had less severe disease. Another reason might be that combination therapy has not been comprehensively studied in distal CTEPH [8, 14, 15, 36-39]; it also seems that this group behaves comparable to $\mathrm{PAH}$ [13]. In the International CTEPH registry [8], 20\% of non-operable CTEPH patients received PDE-5 inhibitors, 38\% ERAs, and 5\% a prostanoid, which is comparable to our cohort; however, the present cohort revealed more patients on combination therapy (18\% compared to $7.7 \%)$. This might be due to the fact that the CTEPH registry was published in 2011 whereas combination therapy has become more common in recent years only, despite the lack of evidence. Combination therapy, for example, was not allowed in the PATENT or Benefit study, the only randomised controlled trials which were available during the treatment period of this cohort and which focused on medical therapy (rio-
8 Respiration DOI: $10.1159 / 000488000$
Bartenstein/Saxer/Appenzeller/Lichtblau/ Schwarz/Ulrich 
ciguat or bosentan) in inoperable CTEPH $[14,37]$. A recent randomised controlled trial assessing the efficacy of the ERA macitentan on distal CTEPH allowed inclusion of patients pretreated with PDE-5 inhibitors in the group of patients in functional class III, and could show that $46 \%$ of pretreated patients improved pulmonary vascular resistance after 16 weeks as the primary outcome, whereas the patients receiving mere macitentan did not (potentially due to their milder disease in functional class II) [40]. Despite these encouraging results, the evidence on combination therapy in distal CTPEH remains scarce and is mainly derived from registries and uncontrolled prospective trials only $[15,18,23]$. Therefore, the use of combination therapy in patients with CTEPH is still off-label and therefore not so widely used.

In the present cohort of PAH and distal CTEPH patients, the change of risk factor profiles did not significantly differ from diagnosis to the last prevalent visit between patients treated with single and combination therapy. We interpret this fact as an indication that combination therapy was started as a goal-oriented strategy in patients with a more advanced disease and therefore patients receiving combination therapy did not reach a better risk factor profile, but were potentially hindered in declining further.

\section{Course of Risk Factor Profiles over the Observational Period}

In this cohort of prevalent PAH patients, the average NYHA class improved significantly over time and the 6MWD and NYHA class stabilised, which is reassuring in this chronic disease with dismal prognosis without therapy $[18,41]$. The same results were consistently found when analysing the course of these parameters under therapy only in PAH patients with more complete datasets who were closely followed up in our tertiary care centre (around half of the cohort). As in the overall cohort, this subgroup demonstrated an improved NYHA class over time under therapy, whereas the $6 \mathrm{MWD}$ remained stable (Tables 1,5$)$. NTproBNP is secreted by cardiac myocytes upon volume overload of the ventricle and has been shown to be a prognostic marker in $\mathrm{PH}$ and heart failure, and is commonly used to monitor the disease course [42-44]. In this cohort, we could show that starting from 1 year under therapy until the prevalent visit, NTproBNP decreased and remained normalised in a major proportion of $\mathrm{PAH}$ patients until the last visit of the observational period [45], which in addition to the stabilisation of exercise capacity and the improved functional class points towards haemodynamic stabilisation in these patients.

Risk Factor Profiles on Drugs in PAH and $\mathrm{CTEPH}$
The improvement in NYHA class under medical therapy and stabilisation of the 6MWD and NTproBNP were also found in distal CTEPH, again indicating that these groups share response to therapy and pointing towards a common pathogenetic end pathway in these two disorders $[13,46,47]$.

\section{Therapeutic Goals}

According to the latest $\mathrm{PH}$ guidelines, a comprehensive risk assessment is required to provide prognostic information [3]. An estimated 1-year mortality rate of $<5 \%$ is considered as low risk and is therefore the aspired clinical status under treatment. NYHA class $\leq$ II, NTproBNP $<300 \mathrm{ng} / \mathrm{L}$, and $6 \mathrm{MWD}>440 \mathrm{~m}$ are three therapeutic goals which are simple to measure and widely available during most routine follow-up visits. We thus focused on these three basic goals in the present study. At the time of diagnosis of this prevalent cohort, the number of fulfilled goals was already considerable. This might be attributed to an increasing awareness of $\mathrm{PH}$ during recent years in the primary care setting and reflects early diagnosis in the excellent, albeit very expensive, Swiss health care system. Under drug therapy and medical follow-up, the number of patients with $\mathrm{PAH}$ who fulfilled all three goals increased by $20 \%$, and the number of patients who fulfilled no criterion decreased by $11 \%$ in this cohort under advanced medical therapy. The main improvement was found in the NYHA goal $(+17 \%)$ and NTproBNP goal $(+18 \%)$, whereas the $6 \mathrm{MWD}$ goal revealed an increase of $+5 \%$. This corresponds with the almost unchanged median 6MWD from baseline to last visit in this already relatively well-performing prevalent cohort. The goal achievements found in distal CTEPH were comparable to those in PAH.

\section{Limitations}

Due to the real-life cohort design of this study, the number of patients at each visit varied. Although all patients had data available at diagnosis and the last prevalent visit, only a subgroup had more complete data registered over consecutive visits. Therefore, the interpretation of the therapeutic goals in the course of the follow-up has to be cautiously interpreted.

This study presents information from a real-life cohort retrieving data from a tertiary care $\mathrm{PH}$ clinic, which however consists of a relatively limited number of patients that is not constant at the different follow-up time points. Risk factor profiles from these prevalent patients were not prospectively assessed within a clinical trial and there was no randomisation (e.g., of different treatment modalities 
or single vs. combination therapy). Thus, these data are susceptible to selection bias and confounders and interpretation must account for this. Nevertheless, real-life data are important, as many patients in real life would not fulfil inclusion criteria for clinical trials due to comorbidities and other reasons.

\section{Conclusion}

In this real-life cohort of prevalent patients with $\mathrm{PAH}$ or distal CTEPH, a stabilisation or improvement of risk factor profiles and an increasing percentage of reached therapeutic goals was found in the course of the disease under drug therapy. Patients with PAH are more likely to have a double combination therapy, whereas patients with CTEPH are mainly treated with a single drug. Whether more aggressive combination therapy would further improve goals in lower risk classes also remains to be determined.

\section{Financial Disclosure and Conflicts of Interest}

S.U. receives grants from the Swiss National Science Foundation, Zurich Lung, Actelion SA, and Orpha Swiss, all of which are not related to the present work. All other authors have no financial support and all have no conflicts of interest.

\section{References}

1 Cenedese E, Speich R, Dorschner L, Ulrich S, Maggiorini M, Jenni R, Fischler M: Measurement of quality of life in pulmonary hypertension and its significance. Eur Respir J 2006;28: 808-815.

2 Cima K, Twiss J, Speich R, McKenna SP, Grunig E, Kahler CM, Ehlken N, Treder U, Crawford SR, Huber LC, et al: The German adaptation of the Cambridge Pulmonary Hypertension Outcome Review (CAMPHOR). Health Qual Life Outcomes 2012;10:110.

-3 Galiè N, Humbert M, Vachiery JL, Gibbs S, Lang I, Torbicki A, Simonneau G, Peacock A, Vonk Noordegraaf A, Beghetti M, et al: 2015 ESC/ERS guidelines for the diagnosis and treatment of pulmonary hypertension. The Joint Task Force for the Diagnosis and Treatment of Pulmonary Hypertension of the European Society of Cardiology (ESC) and the European Respiratory Society (ERS). Eur Respir J 2015;46:1855-1856.

4 Boucly A, Weatherald J, Savale L, Jais X, Cottin V, Prevot G, Picard F, de Groote P, Jevnikar M, Bergot E, et al: Risk assessment, prognosis and guideline implementation in pulmonary arterial hypertension. Eur Respir J 2017;50:1700889.

-5 Kylhammar D, Kjellstrom B, Hjalmarsson C, Jansson K, Nisell M, Soderberg S, Wikstrom G, Radegran G, SveFph, Spahr: A comprehensive risk stratification at early follow-up determines prognosis in pulmonary arterial hypertension. Eur Heart J 2017, Epub ahead of print.

6 Hoeper MM, Kramer T, Pan Z, Eichstaedt CA, Spiesshoefer J, Benjamin N, Olsson KM, Meyer K, Vizza CD, Vonk-Noordegraaf A, et al: Mortality in pulmonary arterial hypertension: prediction by the 2015 European pulmonary hypertension guidelines risk stratification model. Eur Respir J 2017;50:1700740.
7 Kim NH, Delcroix M, Jenkins DP, Channick R, Dartevelle P, Jansa P, Lang I, Madani MM, Ogino H, Pengo V, et al: Chronic thromboembolic pulmonary hypertension. J Am Coll Cardiol 2013;62:D92-D99.

8 Pepke-Zaba J, Delcroix M, Lang I, Mayer E, Jansa P, Ambroz D, Treacy C, D’Armini AM, Morsolini M, Snijder R, et al: Chronic thromboembolic pulmonary hypertension (CTEPH): results from an international prospective registry. Circulation 2011;124:19731981.

-9 Archibald CJ, Auger WR, Fedullo PF, Channick RN, Kerr KM, Jamieson SW, Kapelanski DP, Watt CN, Moser KM: Long-term outcome after pulmonary thromboendarterectomy. Am J Respir Crit Care Med 1999;160: 523-528.

10 Olsson KM, Wiedenroth CB, Kamp JC, Breithecker A, Fuge J, Krombach GA, Haas M, Hamm C, Kramm T, Guth S, et al: Balloon pulmonary angioplasty for inoperable patients with chronic thromboembolic pulmonary hypertension: the initial German experience. Eur Respir J 2017;49:1602409.

11 Mizoguchi H, Ogawa A, Munemasa M, Mikouchi $\mathrm{H}$, Ito H, Matsubara H: Refined balloon pulmonary angioplasty for inoperable patients with chronic thromboembolic pulmonary hypertension. Circ Cardiovasc Interv 2012;5:748-755.

12 Galie N, Humbert M, Vachiery JL, Gibbs S, Lang I, Torbicki A, Simonneau G, Peacock A, Vonk Noordegraaf A, Beghetti M, et al: 2015 ESC/ERS guidelines for the diagnosis and treatment of pulmonary hypertension. Rev Esp Cardiol (Engl Ed) 2016;69:177.

13 Ulrich S, Fischler M, Speich R, Popov V, Maggiorini $\mathrm{M}$ : Chronic thromboembolic and pulmonary arterial hypertension share acute vasoreactivity properties. Chest 2006; 130 :841846.
14 Ghofrani HA, D'Armini AM, Grimminger F, Hoeper MM, Jansa P, Kim NH, Mayer E, Simonneau G, Wilkins MR, Fritsch A, et al: Riociguat for the treatment of chronic thromboembolic pulmonary hypertension. N Engl J Med 2013;369:319-329.

15 Ulrich S, Speich R, Domenighetti G, Geiser T, Aubert JD, Rochat T, Huber L, Treder U, Fischler M: Bosentan therapy for chronic thromboembolic pulmonary hypertension. A national open label study assessing the effect of bosentan on haemodynamics, exercise capacity, quality of life, safety and tolerability in patients with chronic thromboembolic pulmonary hypertension (BOCTEPH-Study). Swiss Med Wkly 2007;137:573-580.

16 Galie N, Barbera JA, Frost AE, Ghofrani HA, Hoeper MM, McLaughlin VV, Peacock AJ, Simonneau G, Vachiery JL, Grunig E, et al: Initial use of ambrisentan plus tadalafil in pulmonary arterial hypertension. N Engl J Med 2015;373:834-844.

17 Sitbon O, Sattler C, Bertoletti L, Savale L, Cottin V, Jais X, De Groote P, Chaouat A, Chabannes $C$, Bergot E, et al: Initial dual oral combination therapy in pulmonary arterial hypertension. Eur Respir J 2016;47:1727-1736.

18 Mueller-Mottet S, Stricker H, Domenighetti G, Azzola A, Geiser T, Schwerzmann M, Weilenmann D, Schoch O, Fellrath JM, Rochat T, et al: Long-term data from the Swiss pulmonary hypertension registry. Respiration 2015; 89:127-140.

-19 Barst RJ, McGoon MD, Elliott CG, Foreman AJ, Miller DP, Ivy DD: Survival in childhood pulmonary arterial hypertension: insights from the registry to evaluate early and longterm pulmonary arterial hypertension disease management. Circulation 2012;125:113-122. 
20 Benza RL, Miller DP, Gomberg-Maitland M, Frantz RP, Foreman AJ, Coffey CS, Frost A, Barst RJ, Badesch DB, Elliott CG, et al: Predicting survival in pulmonary arterial hypertension: insights from the Registry to Evaluate Early and Long-Term Pulmonary Arterial Hypertension Disease Management (REVEAL). Circulation 2010;122:164-172.

-21 Humbert M, Sitbon O, Chaouat A, Bertocchi M, Habib G, Gressin V, Yaici A, Weitzenblum E, Cordier JF, Chabot F, et al: Pulmonary arterial hypertension in France: results from a national registry. Am J Respir Crit Care Med 2006;173:1023-1030.

22 Humbert M, Sitbon O, Yaici A, Montani D, O'Callaghan DS, Jais X, Parent F, Savale L, Natali D, Gunther S, et al: Survival in incident and prevalent cohorts of patients with pulmonary arterial hypertension. Eur Respir J 2010; 36:549-555

23 Fischler M, Speich R, Dorschner L, Nicod L, Domenighetti G, Tamm M, Rochat T, Aubert JD, Ulrich S, Swiss Society for Pulmonary Hypertension: Pulmonary hypertension in Switzerland: treatment and clinical course. Swiss Med Wkly 2008;138:371-378.

-24 Hoeper MM, Huscher D, Ghofrani HA, Delcroix M, Distler O, Schweiger C, Grunig E, Staehler G, Rosenkranz S, Halank M, et al: Elderly patients diagnosed with idiopathic pulmonary arterial hypertension: results from the COMPERA registry. Int J Cardiol 2013; 168:871-880.

25 Hurdman J, Condliffe R, Elliot CA, Davies C, Hill C, Wild JM, Capener D, Sephton P, Hamilton N, Armstrong IJ, et al: ASPIRE registry: assessing the spectrum of pulmonary hypertension identified at a referral centre. Eur Respir J 2012;39:945-955.

-26 Nickel N, Golpon H, Greer M, Knudsen L, Olsson K, Westerkamp V, Welte T, Hoeper MM: The prognostic impact of follow-up assessments in patients with idiopathic pulmonary arterial hypertension. Eur Respir J 2012; 39:589-596.

-27 Ling Y, Johnson MK, Kiely DG, Condliffe R, Elliot CA, Gibbs JS, Howard LS, Pepke-Zaba J, Sheares KK, Corris PA, et al: Changing demographics, epidemiology and survival of incident pulmonary arterial hypertension. Am J Respir Crit Care Med 2012;186:790-796.

-28 McGoon MD, Benza RL, Escribano-Subias P, Jiang X, Miller DP, Peacock AJ, Pepke-Zaba J, Pulido T, Rich S, Rosenkranz S, et al: Pulmonary arterial hypertension: epidemiology and registries. J Am Coll Cardiol 2013;62:D51D59.
9 McGoon MD, Miller DP: REVEAL: a contemporary US pulmonary arterial hypertension registry. Eur Respir Rev 2012;21:8-18.

30 Muller-Mottet S, Hasler E, Opitz I, Weder W, Schuepbach R, Speich R, Ulrich S: Chronic thromboembolic pulmonary hypertension. Cardiovasc Med 2014;17:328-333.

-31 Escribano-Subias P, Blanco I, Lopez-Meseguer M, Lopez-Guarch CJ, Roman A, Morales P, Castillo-Palma MJ, Segovia J, Gomez-Sanchez MA, Barbera JA, et al: Survival in pulmonary hypertension in Spain: insights from the Spanish registry. Eur Respir J 2012;40:596-603.

32 Badesch DB, Raskob GE, Elliott CG, Krichman AM, Farber HW, Frost AE, Barst RJ, Benza RL, Liou TG, Turner M, et al: Pulmonary arterial hypertension: baseline characteristics from the REVEAL Registry. Chest 2010;137:376-387.

33 Hoeper MM, Markevych I, Spiekerkoetter E, Welte T, Niedermeyer J: Goal-oriented treatment and combination therapy for pulmonary arterial hypertension. Eur Respir J 2005; 26:858-863.

34 Thenappan T, Shah SJ, Rich S, Gomberg-Maitland M: A USA-based registry for pulmonary arterial hypertension: 1982-2006. Eur Respir J 2007;30:1103-1110.

35 Pulido T, Adzerikho I, Channick RN, Delcroix M, Galie N, Ghofrani HA, Jansa P, Jing ZC, Le Brun FO, Mehta S, et al: Macitentan and morbidity and mortality in pulmonary arterial hypertension. N Engl J Med 2013;369: 809-818.

36 Hoeper MM, Kramm T, Wilkens H, Schulze C, Schafers HJ, Welte T, Mayer E: Bosentan therapy for inoperable chronic thromboembolic pulmonary hypertension. Chest 2005; 128:2363-2367.

37 Jais X, D’Armini AM, Jansa P, Torbicki A, Delcroix M, Ghofrani HA, Hoeper MM, Lang IM, Mayer E, Pepke-Zaba J, et al: Bosentan for treatment of inoperable chronic thromboembolic pulmonary hypertension: BENEFiT (bosentan effects in inoperable forms of chronic thromboembolic pulmonary hypertension), a randomized, placebo-controlled trial. J Am Coll Cardiol 2008;52:2127-2134.

38 Suntharalingam J, Treacy CM, Doughty NJ, Goldsmith K, Soon E, Toshner MR, Sheares KK, Hughes R, Morrell NW, Pepke-Zaba J: Long-term use of sildenafil in inoperable chronic thromboembolic pulmonary hypertension. Chest 2008;134:229-236.
39 Simonneau G, D’Armini AM, Ghofrani HA, Grimminger F, Hoeper MM, Jansa P, Kim $\mathrm{NH}$, Wang C, Wilkins MR, Fritsch A, et al: Riociguat for the treatment of chronic thromboembolic pulmonary hypertension: a longterm extension study (CHEST-2). Eur Respir J 2015;45:1293-1302.

40 Ghofrani HA, Simonneau G, D’Armini AM, Fedullo P, Howard LS, Jais X, Jenkins DP, Jing ZC, Madani MM, Martin N, et al: Macitentan for the treatment of inoperable chronic thromboembolic pulmonary hypertension (MERIT-1): results from the multicentre, phase 2, randomised, double-blind, placebocontrolled study. Lancet Respir Med 2017;5: 785-794.

41 D’Alonzo GE, Barst RJ, Ayres SM, Bergofsky $\mathrm{EH}$, Brundage BH, Detre KM, Fishman AP, Goldring RM, Groves BM, Kernis JT et al: Survival in patients with primary pulmonary hypertension. Results from a national prospective registry. Ann Intern Med 1991;115: 343-349.

42 Leuchte HH, Baumgartner RA, Nounou ME, Vogeser M, Neurohr C, Trautnitz M, Behr J: Brain natriuretic peptide is a prognostic parameter in chronic lung disease. Am J Respir Crit Care Med 2006;173:744-750.

43 Leuchte HH, El Nounou M, Tuerpe JC, Hartmann B, Baumgartner RA, Vogeser M, Muehling $\mathrm{O}$, Behr J: N-terminal pro-brain natriuretic peptide and renal insufficiency as predictors of mortality in pulmonary hypertension. Chest 2007;131:402-409.

44 Warwick G, Thomas PS, Yates DH: Biomarkers in pulmonary hypertension. Eur Respir J 2008;32:503-512.

45 Raymond I, Groenning BA, Hildebrandt PR, Nilsson JC, Baumann M, Trawinski J, Pedersen F: The influence of age, sex and other variables on the plasma level of $\mathrm{N}$-terminal pro brain natriuretic peptide in a large sample of the general population. Heart 2003;89:745751.

46 Humbert M, Morrell NW, Archer SL, Stenmark KR, MacLean MR, Lang IM, Christman BW, Weir EK, Eickelberg O, Voelkel NF, et al: Cellular and molecular pathobiology of pulmonary arterial hypertension. J Am Coll Cardiol 2004;43:13S-24S.

47 Humbert M: Pulmonary arterial hypertension and chronic thromboembolic pulmonary hypertension: pathophysiology. Eur Respir Rev 2010;19:59-63. 